\title{
Role of HOTAIR in the diagnosis and prognosis of acute leukemia
}

\author{
YUAN-YUAN ZHANG, SI-HAN HUANG, HUA-RONG ZHOU, CONG-JIE CHEN, \\ LI-HONG TIAN and JIAN-ZHEN SHEN
}

Fujian Institute of Hematology, Fujian Provincial Key Laboratory on Hematology, Fujian Medical University Union Hospital, Fuzhou, Fujian 350001, P.R. China

Received April 8,2016; Accepted August 16, 2016

DOI: $10.3892 /$ or.2016.5147

\begin{abstract}
HOX antisense intergenic RNA (HOTAIR), a long non-coding RNA, plays an important role in the development of many types of cancers. Its function in acute leukemia (AL), however, has not been examined. The present study investigated the role of HOTAIR and its downstream genes in AL, and determined whether it could act as a molecular marker for prediction of leukemia development and prognosis. Real-time quantitative PCR was used to examine the expression of each gene in the HOTAIR signaling pathway in AL patients. The relationship between expression of HOTAIR and downstream genes and AL prognosis was analyzed. Expression of HOTAIR in patients with acute monocytic leukemia (M5) was increased as compared to controls $(\mathrm{P}<0.05)$. Compared to patients with low HOTAIR expression, overall survival and event-free survival of patients with high HOTAIR expression was significantly reduced. In addition, the expression of downstream genes in the HOTAIR signaling pathway including EZH2, LSD1, DNMT3A and DNMT3B was significantly increased in AL patients, and showed a significant positive correlation with high expression of HOTAIR $(\mathrm{P}<0.05)$. In conclusion, HOTAIR was closely related with a poor prognosis in $\mathrm{AL}$ patients. It
\end{abstract}

Correspondence to: Dr Jian-Zhen Shen, Fujian Institute of Hematology, Fujian Provincial Key Laboratory on Hematology, Fujian Medical University Union Hospital, 29 Xin Quan Road, Fuzhou, Fujian 350001, P.R. China

E-mail: doctorsjz@163.com

Abbreviations: AL, acute leukemia; AML, acute myelogenous leukemia; ALL, acute lymphoblastic leukemia; M0, acute myeloid leukemia with minimal differentiation; M1, AML with partial differentiation; M2, AML with maturation; M3, acute promyelocytic leukemia; M4, acute myelomonocytic leukemia with granules; M5, acute monocytic leukemia; M6, acute erythroleukemia; NC, normal control; lncRNA, long non-coding RNA; HOTAIR, HOX antisense intergenic RNA; DNMTs, DNA methyltransferases; PRC2, polycomb repressive complex 2; LSD1, lysine-specific demethylase 1; RT-qPCR, reverse transcription-quantitative PCR

Key words: long non-coding RNA, HOTAIR, acute leukemia, epigenetics may be involved in the development of leukemia by mediating methylation of DNA and histones.

\section{Introduction}

Acute leukemia (AL) is a malignant clonal disease of hematopoietic stem cells. The incidence rate of leukemia in China is 5.68/100,000, and it is the leading cause of cancer-related mortality in children and adults under the age of 35 (1). Recent progress in medical sciences and therapeutic approaches such as chemotherapy, radiotherapy, biological regulation and hematopoietic stem cell transplantation has resulted in significant advancements; however, leukemia continues to be a significant health burden. An effective molecular marker for early diagnosis, prognosis and treatment guidance, is therefore, urgently required.

Numerous studies have shown that epigenetic abnormalities play an important role in the development and progression of AL (2). Non-coding RNA has increasingly been shown to play an important role in epigenetic regulation. Long non-coding RNAs (lncRNAs) are a class of RNA more than 200 nucleotides in length that lack an open reading frame and protein coding function, most of which are transcribed by RNA polymerase II (3). IncRNAs can regulate gene expression at the level of epigenetics, transcription and post-transcription, participate in X chromosome inactivation, genomic imprinting, chromatin modification, transcription activation, transcription interference, nuclear transport and a variety of important regulatory processes. IncRNAs are closely involved with the onset, development and pathogenesis of human diseases (4-7).

In 2007, Rinn et al (8) were the first to identify an IncRNA regulating gene expression in trans at the HOXC gene locus on chromosome 12. The lncRNA is involved in regulation of HOX gene clusters located on different chromosomes rather than cis-regulation in the HOXC locus and was, therefore, named HOX antisense intergenic RNA (HOTAIR). Gupta et al (9) subsequently found that the expression level of HOTAIR in breast cancer metastases was significantly higher than in primary breast cancer and normal breast tissues, and that the high expression of HOTAIR was associated with metastasis and a poor prognosis for patients. An additional two studies on breast cancer reached similar conclusions $(10,11)$. Further studies showed that expression levels of HOTAIR were also significantly increased in colorectal cancer (12), hepatocellular carcinoma (13), lung (14), pancreatic (15) and nasopharyngeal 
cancer (16), and other malignant tumors and metastases. Furthermore, cancer patients with high HOTAIR expression had lower survival rates and higher recurrence rates (17). These studies suggested that HOTAIR was involved in tumorigenesis, and had significant clinical importance.

Studies have shown that HOTAIR epigenetically regulates gene expression, acting as a scaffold for protein complexes in both PRC2 and LSD1-mediated target gene silencing. PRC2, a member of PcG family, consists of the core elements EZH2, EED and SUZ12, as well as histone binding protein RbAp46 and PHFl.EZH2 is an important subunit with catalytic activity, with a highly conserved SET structural domain that methylates the 9th and 27th lysine in the nucleosome histone H3, thereby inhibiting hundreds of genes. These include genes involved in cell growth, differentiation, tumor metastasis and expression of related genes. SUZ12 and EED maintain the stability of the complex, and are essential components in the catalysis of PRC2 complexes (18). The LSD1 complex is comprised of LSD1, REST, CoREST, HDAC1-2, BHC80 and BRAF35 (19,20). LSD1 removes the methyl groups on $\mathrm{H} 3 \mathrm{~K} 4 \mathrm{me} 1 / 2$ and $\mathrm{H} 3 \mathrm{~K} 9 \mathrm{me} 1 / 2$, resulting in a single methyl group or no methyl group, thereby regulating transcription of downstream genes (21). REST, as a DNA-binding protein, is involved in localization of the LSD1 complex to the correct genomic location. CoREST can bind with nucleosomes, and recruit LSD1 to demethylate $\mathrm{H} 3 \mathrm{~K} 4$. Together, these proteins cooperatively inhibit transcription.

Although HOTAIR has been implicated in the onset of a variety of tumors, its role in hematological tumor formation remains unclear. To date, its significance in terms of diagnosis and prognosis in leukemia has not been extensively studied. HOTAIR acts as a scaffold for histone modification complexes and is involved in epigenetic gene regulation (22). The present study aimed to examine whether expression of DNA methyltransferases and histone methyltransferases in leukemia patients was modulated by HOTAIR, and whether HOTAIR could act as a diagnostic/prognostic marker for leukemia.

\section{Materials and methods}

Patients. Ninety-six bone marrow cell samples were collected from patients diagnosed with leukemia and treated at the Affiliated Union Hospital of Fujian Medical University between October 2011 and February 2015. Patients included 56 males and 40 females between the ages of 14 and 84 Seventy-three cases were acute myelogenous leukemia and 23 cases were acute lymphoblastic leukemia. Eighty bone marrow samples from bone marrow donors and patients with non-hematologic malignancies were studied as controls. All specimens were obtained with approval from the Medical Ethics Committee and the patients informed consent. Inclusion criteria were as follows: i) diagnosis and classification of $\mathrm{AL}$ according to the French-American-British (FAB) classification criteria; ii) confirmation of the AL diagnosis by morphology, immunophenotyping, cytogenetics, molecular cell biology (MICM) and additional examinations. Cases of transformation of myelodysplastic syndrome (MDS) and acute transformation of chronic myelogenous leukemia (CML) were excluded; iii) patients had no other types of malignant tumors or contraindications to bone marrow puncture. Evaluation criteria for efficacy were based on 'Diagnosis and Treatment Standards of Blood Disease', compiled by Zhang Zhinan. Prognosis was based on standards recommended by the European Leukemia Working Group (23).

Extraction of mononuclear cells from bone marrow. Following bone marrow puncture, $5 \mathrm{ml}$ of bone marrow was harvested using sterile procedures and added to a tube containing $0.2 \mathrm{ml}$ heparin. Mononuclear cells in bone marrow were isolated using lymphocyte separation medium (Hao Yang in Tianjin). The cell pellet was processed for extraction of DNA, RNA and proteins, or was stored at $-80^{\circ} \mathrm{C}$ for later use.

Extraction of total cellular RNA and cDNA synthesis. TRIzol reagent (Invitrogen, Carlsbad, CA, USA) was used to extract RNA. Two microliters of RNA was used to measure concentration and purity on a quantitation analyzer for nucleic acids. Purity of RNA was confirmed by OD260/280 ratios between 1.8-2.0. RNA was immediately reverse transcribed (Thermo Fisher Scientific, Inc., Waltham, MA, USA) to cDNA. A PCR tube was used, RNA $(1 \mu \mathrm{g})$ was added, random primer $1 \mu \mathrm{l}$, diethylpyrocarbonate (DEPC) water to $12 \mu \mathrm{l} ; 65^{\circ} \mathrm{C}$ water bath for $5 \mathrm{~min}$ and quickly returned to ice for cooling; then $5 \mathrm{X}$ reverse transcriptase buffer $4 \mu \mathrm{l}$ was added, $10 \mathrm{mM}$ dNTP mix $2 \mu \mathrm{l}$, reverse transcriptase $1 \mu \mathrm{l}$, RNase inhibitor $1 \mu \mathrm{l}$ to the total volume was $20 \mu \mathrm{l}$. The reaction conditions were: $25^{\circ} \mathrm{C}$ for $5 \mathrm{~min}, 42^{\circ} \mathrm{C}$ for $60 \mathrm{~min}, 70^{\circ} \mathrm{C}$ for $5 \mathrm{~min}$ and the temperature was then decreased to $4^{\circ} \mathrm{C}$. The cDNA was either immediately used as a template for PCR or stored at $-20^{\circ} \mathrm{C}$ for later use.

Detection of changes in $m R N A$ levels using real-time PCR. Real-time PCR (ABI 7500) was performed to detect expression of the lncRNA HOTAIR, PRC2 complex (EZH2, SUZ12 and EED), LSD1 complex (LSD1, REST and CoREST), and methyltransferase (DNMT3A and DNMT3B) genes. The total reaction volume was $25 \mu \mathrm{l}$, and included $12.5 \mu \mathrm{l}$ SYBR-Green qPCR Mix (Roche), $1 \mu \mathrm{l}$ cDNA, $0.75 \mu \mathrm{l}$ each of forward and reverse primers at $10 \mu \mathrm{mol} / 1$ (Table I), and DEPC water to $25 \mu \mathrm{l}$. Cycling parameters were as follows: $50^{\circ} \mathrm{C}$ for $2 \mathrm{~min}$ for 1 cycle; $95^{\circ} \mathrm{C}$ for $2 \mathrm{~min}$ for $1 \mathrm{cycle} ; 95^{\circ} \mathrm{C}$ for $15 \mathrm{sec}$, then $60^{\circ} \mathrm{C}$ for $30 \mathrm{sec}$ for 40 cycles; melting curve analysis at $95^{\circ} \mathrm{C}$ for $15 \mathrm{sec}, 60^{\circ} \mathrm{C}$ for $1 \mathrm{~min}, 95^{\circ} \mathrm{C}$ for $15 \mathrm{sec}, 60^{\circ} \mathrm{C}$ for $15 \mathrm{sec}$ for $1 \mathrm{cycle}$. GAPDH was used as an internal reference. Quantification of mRNA expression levels was performed by comparison of $\mathrm{Ct}$ values. Copy numbers were normalized to GAPDH and the $\Delta \mathrm{Ct}$ of target genes calculated as the average $\mathrm{Ct}$ value of target genes - average $\mathrm{Ct}$ value of reference genes. The mean was obtained and the relative expression values calculated using the $2^{-\Delta \mathrm{Ct}}$ method and differences compared.

Statistical analysis. Statistical software including SPSS 22.0 and GraphPad Prism 6.0 was used for data analysis. Quantitative data are expressed as mean \pm standard deviation or median \pm interquartile range, and qualitative data as the number of cases and percentages. The two groups were compared using the Mann-Whitney $U$ test, while multiple groups were compared using the Kruskal-Wallis $\mathrm{H}$ test, and rates were compared and analyzed by the Chi-square or Fisher's exact tests. The Kaplan-Meier method and log-rank test was adopted to compare differences in survival time. Variables 
Table I. Primer sequences for qRT-PCR.

\begin{tabular}{|c|c|c|c|c|}
\hline Gene & & Primer $\left(5^{\prime}-3^{\prime}\right)$ & Product size (bp) & Gene accession no. \\
\hline GAPDH & $\begin{array}{l}\text { Forward } \\
\text { Reverse }\end{array}$ & $\begin{array}{l}\text { CCCСTTCATTGACCTCAACTACAT } \\
\text { CGCTCCTGGAAGATGGTGA }\end{array}$ & 135 & NM_002046.4 \\
\hline HOTAIR & $\begin{array}{l}\text { Forward } \\
\text { Reverse }\end{array}$ & $\begin{array}{l}\text { GGTAGAAAAAGCAACCACGAAGC } \\
\text { ACATAAACCTCTGTCTGTGAGTGCC }\end{array}$ & 169 & NR_047517.1 \\
\hline$E Z H 2$ & $\begin{array}{l}\text { Forward } \\
\text { Reverse }\end{array}$ & $\begin{array}{l}\text { GGAACAACGCGAGTCGG } \\
\text { CTGATTTTACACGCTTCCGC }\end{array}$ & 101 & NM_004456.4 \\
\hline Suz12 & $\begin{array}{l}\text { Forward } \\
\text { Reverse }\end{array}$ & $\begin{array}{l}\text { GCATTGCCCTTGGTGTACTC } \\
\text { TGGTCCGTTGCGACTAAAA }\end{array}$ & 214 & NM_015355.2 \\
\hline$E E D$ & $\begin{array}{l}\text { Forward } \\
\text { Reverse }\end{array}$ & $\begin{array}{l}\text { GTGTGCGATGGTTAGGCG } \\
\text { GTCACATTAGATTCACTGGGTTT }\end{array}$ & 120 & NM_003797.3 \\
\hline$L S D 1$ & $\begin{array}{l}\text { Forward } \\
\text { Reverse }\end{array}$ & $\begin{array}{l}\text { ACCACAACAGACCCAGAAGG } \\
\text { GGTGCTTCTAATTGTTGGAGAG }\end{array}$ & 116 & NM_015013.3 \\
\hline$R E S T$ & $\begin{array}{l}\text { Forward } \\
\text { Reverse }\end{array}$ & $\begin{array}{l}\text { GGCACGGAAGGAGCAAGT } \\
\text { GGTGAGAGATCCTCTGTGC }\end{array}$ & 97 & NM_005612.4 \\
\hline CoREST & $\begin{array}{l}\text { Forward } \\
\text { Reverse }\end{array}$ & $\begin{array}{l}\text { CGAGGACTAAAACTAGTGTGATGG } \\
\text { TGCCTCTTCCAGTTCATCCT }\end{array}$ & 86 & NM_015156.3 \\
\hline DNMT3A & $\begin{array}{l}\text { Forward } \\
\text { Reverse }\end{array}$ & $\begin{array}{l}\text { TATTGATGAGCGCACAAGAGAGC } \\
\text { GGGTGTTCCAGGGTAACATTGAG }\end{array}$ & 111 & NM_015355.2 \\
\hline DNMT3B & $\begin{array}{l}\text { Forward } \\
\text { Reverse }\end{array}$ & $\begin{array}{l}\text { GACTCGAAGACGCACAGCTG } \\
\text { CTCGGTCTTTGCCGTTGTTATAG }\end{array}$ & 98 & NM_006892.3 \\
\hline
\end{tabular}

HOTAIR, HOX antisense intergenic RNA.

influencing survival times with significant differences in univariate analysis were analyzed using a Cox proportional hazards model. $\mathrm{P}<0.05$ was considered statistically significant. Overall survival (OS) was measured from the beginning of the trial to the death of the patient (by any cause) or to the date of last follow-up for surviving patients. Event-free survival (EFS) was measured from the beginning of the trial to treatment failure, relapse or death (from any cause). For patients not experiencing these events, EFS was calculated to the date of the last follow-up. For patients who did not reach complete remission, EFS was calculated from the date of the beginning of clinical trials to the date of disease progression or death.

\section{Results}

Expression of HOTAIR in AL patients, and analysis of clinical features and prognosis. The expression of HOTAIR genes in mononuclear cells from 96 patients with AL and 80 controls was examined by RT-qPCR. Our results show that the expression of HOTAIR in acute monocytic leukemia (M5) patients increased relative to controls $(\mathrm{P}=0.0289$; Fig. $1 \mathrm{~A})$, and the increase is greater than in patients with other types of acute myelogenous leukemia (AML; $\mathrm{P}=0.0019$; Fig. 1B). No significant difference is observed when expression is compared to ALL, AML, non-M5 AML patients $(\mathrm{P}=0.7041$; Fig. $1 \mathrm{~B}$; $\mathrm{P}=0.1597, \mathrm{P}=0.6209$; Fig. $1 \mathrm{C})$. Based on a HOTAIR/GAPDH ratio $=0.00098$, patients were divided into a high HOTAIR expression group $(n=19)$ and a low expression group $(n=77$; Fig. 2A) (24), and the clinical features of the two groups were analyzed. Patients from the two groups show no statistically significant differences in gender, age, FAB type (FrenchAmerican-British Classification: A standardized classification system for acute leukemias based on morphology), white blood cell count, hemoglobin, platelets, proportion of juvenile cells in the bone marrow, or risk stratification based on karyotype (Table II). After obtaining consent from the patients families, a telephone follow-up was conducted in combination with inpatient and/or outpatient medical record examination. Follow-up was completed May 30, 2015. The Kaplan-Meier method was used to analyze the association of expression levels of HOTAIR with OS and EFS in AL patients. The results show that, compared with patients with low HOTAIR expression, OS and EFS of patients with high HOTAIR expression significantly decreased $(\mathrm{P}<0.05$; Fig. $2 \mathrm{~B}$ and $\mathrm{C})$. Clinical prognostic indicators were also analyzed. Univariate analysis of OS and EFS shows that age, peripheral blood leucocyte count and the relative level of HOTAIR expression are prognostic indicators, and although the remaining the clinical features were not found to be prognostic indicators, it could be due to an insufficient number of cases (Table III). The characteristics where $\mathrm{P}<0.05$ were subjected to multivariable analysis showed that, for OS and EFS in AL patients, age, peripheral blood leucocyte count and HOTAIR expression are independent prognostic factors (Table IV). 
A

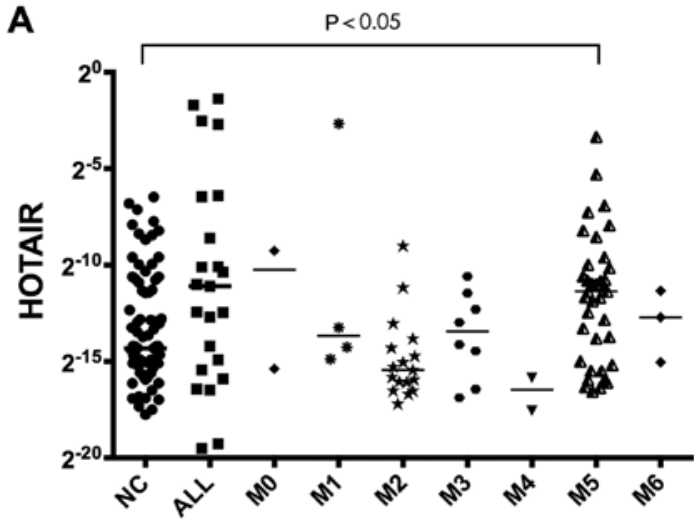

B

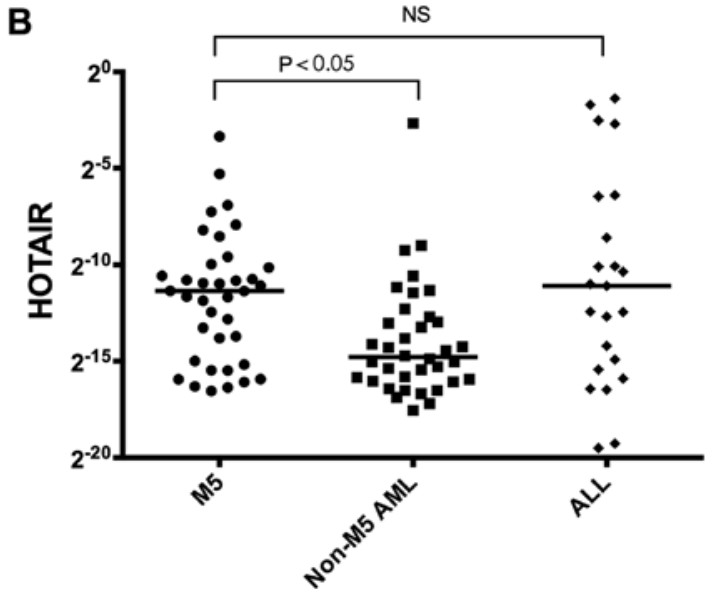

C

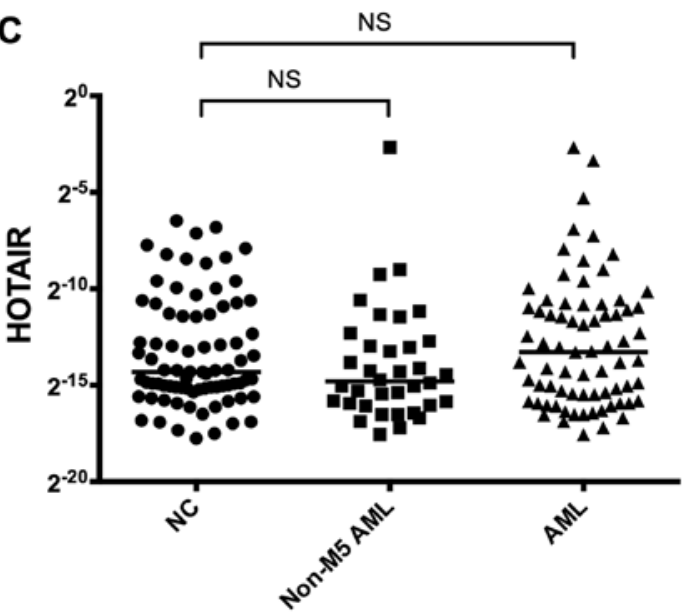

Figure 1. Expression levels of the HOTAIR gene in bone marrow-derived mononuclear cells. (A) HOTAIR expression in controls compared to AL patients; expression of HOTAIR in M5 patients increased compared to controls ( $\mathrm{P}=0.0289$; Kruskal-Wallis $\mathrm{H}$ test). (B) Expression of HOTAIR in M5 patients increased compared to patients with other types of AML patients $(\mathrm{P}=0.0019$; Kruskal-Wallis $\mathrm{H}$ test), while there was no significant difference from levels in ALL patients ( $\mathrm{P}=0.7041$, Kruskal-Wallis $\mathrm{H}$ test). (C) There was no obvious difference of HOTAIR expression in controls compared to non-M5 AML and all AML patients $(\mathrm{P}=0.1597, \mathrm{P}=0.6209$; Kruskal-Wallis $\mathrm{H}$ test).

Expression levels of downstream genes in the HOTAIR signaling pathway. Expression of the PRC2 complex (EZH2, SUZ12 and EED) and the LSD1 complex (LSD1, REST and CoREST), and downstream genes in the HOTAIR signaling pathway was measured by RT-qPCR. Our results show that, compared with normal controls, the expression of EZH2

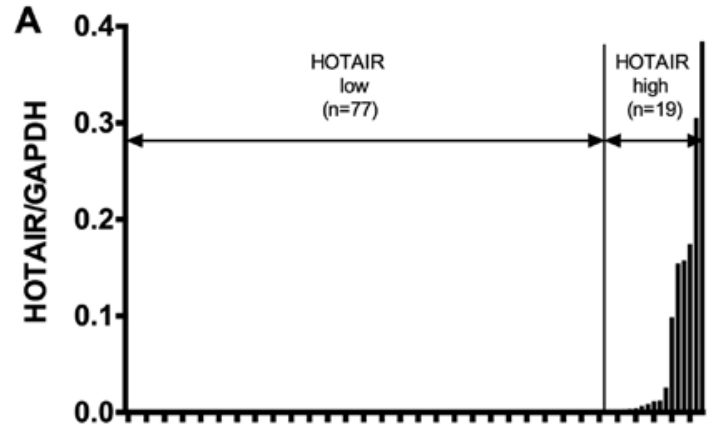

AL patients $(n=96)$
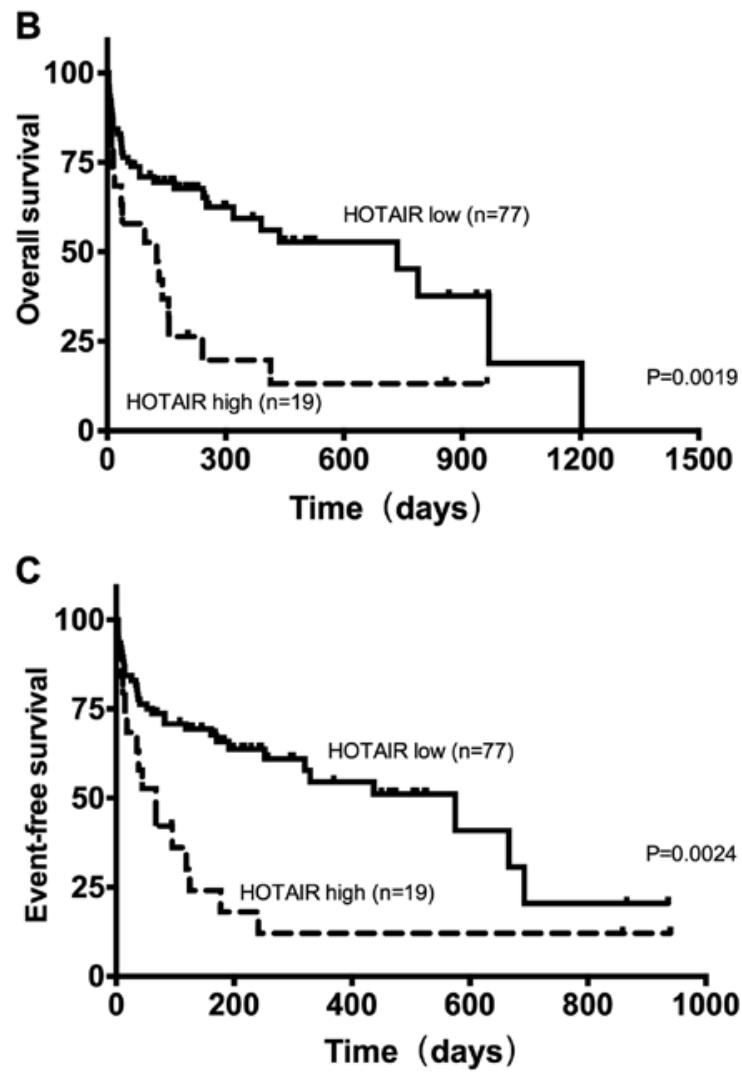

Figure 2. OS and EFS in AL patients. (A) Patients were divided into two groups based on HOTAIR expression levels; high expression of HOTAIR group $(n=19)$ and low expression of HOTAIR group $(n=77)$. (B) The Kaplan-Meier method was used to analyze the association between expression levels of HOTAIR and OS/EFS in AL patients $(n=96)$. The OS of the high HOTAIR expression group was significantly lower than that of the low expression group ( $\mathrm{P}=0.0019, \log$-rank test). (C) Compared to patients with low expression, EFS in patients with high expression of HOTAIR significantly decreased $(\mathrm{P}=0.0024, \log$-rank test).

and LSD1 in AL patients significantly increased $(\mathrm{P}=0.0009$ and $\mathrm{P}=0.0003$, respectively; Fig. $3 \mathrm{~A}$ and $\mathrm{B}$ ), and showed a significant correlation with the high expression of HOTAIR (EZH2, r $=0.5381, \mathrm{P}<0.0001$; LSD1, $\mathrm{r}=0.2603, \mathrm{P}=0.0076$; Fig. 5A and B). Expression of SUZ12 and REST showed no significant differences $(\mathrm{P}=0.5437$ and $\mathrm{P}=0.4265$, respectively; Fig. 3C and D), while expression of EED and CoREST decreased $(\mathrm{P}=0.0213$ and $\mathrm{P}=0.0003$, respectively; Fig. $3 \mathrm{E}$ and $\mathrm{F})$.

Expression levels of DNA methyltransferase genes. DNA methylation plays an important role in the occurrence and progression of leukemia, and expression of DNA 
Table II. HOTAIR expression and clinicopathological characteristics of patients.

\begin{tabular}{|c|c|c|c|}
\hline Factors & $\begin{array}{l}\text { HOTAIR high expression } \\
\qquad(n=19) \mathrm{N}(\%)\end{array}$ & $\begin{array}{l}\text { HOTAIR low expression } \\
\qquad(\mathrm{n}=77) \mathrm{N}(\%)\end{array}$ & P-value \\
\hline \multicolumn{4}{|c|}{ Gender (range/median) } \\
\hline Male & $14(73.7)$ & $42(54.5)$ & \multirow[t]{2}{*}{0.194} \\
\hline Female & $5(26.3)$ & $35(45.5)$ & \\
\hline \multicolumn{4}{|c|}{ Age (years, range/median) } \\
\hline$<60$ & $17(89.5)$ & $63(81.8)$ & \multirow[t]{2}{*}{0.731} \\
\hline$\geq 60$ & $2(10.5)$ & $14(18.2)$ & \\
\hline \multicolumn{4}{|l|}{ FAB classification } \\
\hline AML & $13(68.4)$ & $63(81.8)$ & \multirow[t]{2}{*}{0.216} \\
\hline ALL & $6(31.6)$ & $14(18.2)$ & \\
\hline \multicolumn{4}{|l|}{ WBC (x109/1) } \\
\hline$<100$ & $13(68.4)$ & $59(76.6)$ & \multirow[t]{2}{*}{0.555} \\
\hline$\geq 100$ & $6(31.6)$ & $18(23.4)$ & \\
\hline \multicolumn{4}{|l|}{$\mathrm{HB}(\mathrm{g} / \mathrm{l})$} \\
\hline$<60$ & $4(21.1)$ & $22(28.6)$ & \multirow[t]{2}{*}{0.579} \\
\hline$\geq 60$ & $15(78.9)$ & $55(71.4)$ & \\
\hline \multicolumn{4}{|l|}{ PLT (x109/1) } \\
\hline$<30$ & $10(52.6)$ & $31(40.3)$ & \multirow[t]{2}{*}{0.438} \\
\hline$\geq 30$ & $9(47.4)$ & $46(59.7)$ & \\
\hline \multicolumn{4}{|c|}{ Bone marrow blasts $(\%)$} \\
\hline$<60$ & $3(15.8)$ & $13(16.9)$ & \multirow[t]{2}{*}{1} \\
\hline$\geq 60$ & $16(84.2)$ & $64(83.1)$ & \\
\hline \multicolumn{4}{|c|}{ Risk stratification based on karyotype ${ }^{a}$} \\
\hline Better-risk & 0 & $11(14.3)$ & \multirow[t]{4}{*}{0.075} \\
\hline Intermediate-risk & $7(36.8)$ & $31(40.3)$ & \\
\hline Poor-risk & $2(10.5)$ & $15(19.5)$ & \\
\hline Unknown & $10(52.6)$ & $20(26.0)$ & \\
\hline
\end{tabular}

${ }^{a}$ Better-risk, $\operatorname{inv}(16)$, or $\mathrm{t}(16 ; 16) ; \mathrm{t}(8 ; 21)$; $\mathrm{t}(15 ; 17)$; intermediate-risk, normal cytogenetics; +8 alone; $\mathrm{t}(9 ; 11)$; other non-defined; poor-risk, complex ( $\geq 3$ clonal chromosomal abnormalities); monosomal karyotype, -5, 5q-, -7, 7q-; 11q23-non t(9;11); inv(3), t( $3 ; 3)$; t(6;9); t(9;22). FAB, French-American-British; AML, acute myelogenous leukemia; ALL, acute lymphoblastic leukemia; WBC, white blood cell; PLT, platelet.

Table III. Univariate analysis of OS and EFS of patients with AL.

\begin{tabular}{lccrr}
\hline Characteristic & Group & $\mathrm{n}=$ & P-value (OS) & P-value (EFS) \\
\hline Gender & Male/female & $56 / 40$ & 0.238 & 0.171 \\
Age (years) & $<60 / \geq 60$ & $79 / 17$ & 0.003 & 0.005 \\
FAB classification & AML/ALL & $73 / 23$ & 0.615 & 0.523 \\
WBC $\left(x 10^{9} / \mathrm{l}\right)$ & $<100 / \geq 100$ & $70 / 26$ & $<0.001$ & $<0.001$ \\
HB $(\mathrm{g} / \mathrm{l})$ & $<60 / \geq 60$ & $25 / 71$ & 0.653 & 0.438 \\
PLT (x10 $/$ ) & $<30 / \geq 30$ & $40 / 56$ & 0.251 & 0.265 \\
Bone marrow blasts & $<60 / \geq 60 \%$ & $15 / 81$ & 0.750 & 0.995 \\
HOTAIR & High/low & $19 / 77$ & 0.003 & 0.003 \\
\hline
\end{tabular}

OS, overall survival; EFS, event-free survival; AL, acute leukemia; FAB, French-American-British; AML, acute myelogenous leukemia; ALL, acute lymphoblastic leukemia; WBC, white blood cell; PLT, platelet.

methyltransferase genes directly influences the functions of certain oncogenes and tumor suppressor genes. DNA methyltransferases are divided into two types: DNMT1 maintains DNA methylation while DNMT3A, and DNMT3B 
Table IV. Multivariate analysis of OS and EFS of patients with AL.

\begin{tabular}{lccccccccc}
\hline & & & \multicolumn{4}{c}{ OS } & & \multicolumn{3}{c}{ EFS } \\
Characteristic & Group & No. & HR & $95 \%$ CI & P-value & & HR & $95 \%$ CI & P-value \\
\hline Age (years) & $<60 / \geq 60$ & $79 / 17$ & 0.354 & $0.166-0.758$ & $\mathbf{0 . 0 0 4}$ & & 0.364 & $0.172-0.771$ & $\mathbf{0 . 0 0 6}$ \\
WBC (x 10 $/ 1)$ & $<100 / \geq 100$ & $70 / 26$ & 0.379 & $0.186-0.773$ & $\mathbf{0 . 0 0 1}$ & & 0.438 & $0.219-1.877$ & $\mathbf{0 . 0 0 2}$ \\
HOTAIR & High/low & $19 / 77$ & 2.407 & $1.253-4.624$ & $\mathbf{0 . 0 0 5}$ & & 2.388 & $1.248-4.568$ & $\mathbf{0 . 0 0 5}$ \\
\hline
\end{tabular}

OS, overall survival; EFS, event-free survival; AL, acute leukemia; HR, hazard ratio; CI, confidence interval; WBC, white blood cell.

A

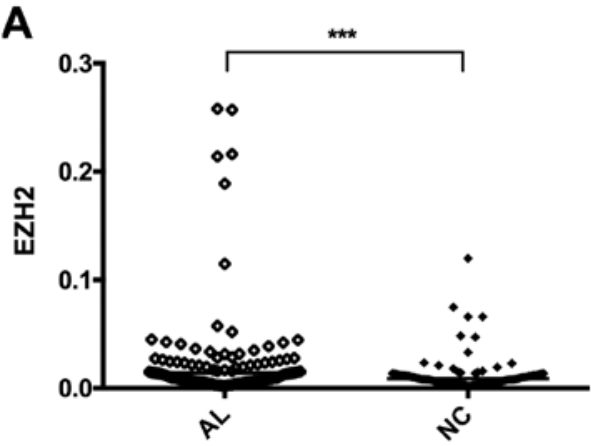

C

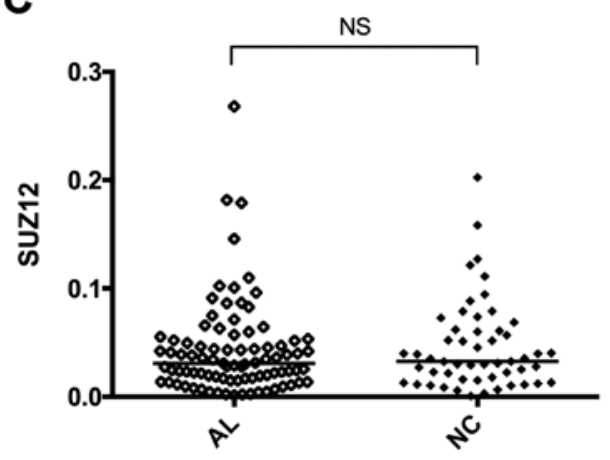

E

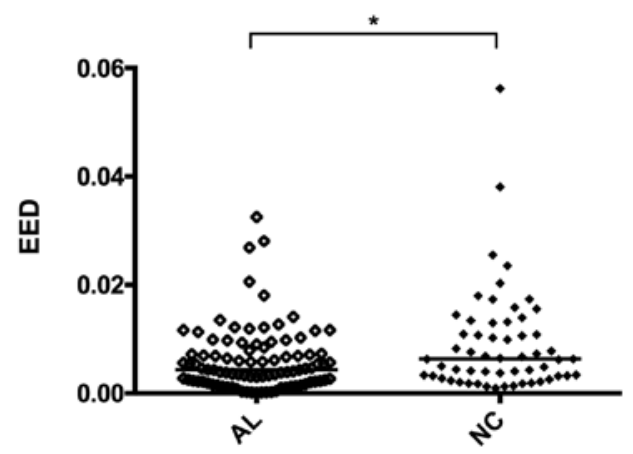

B

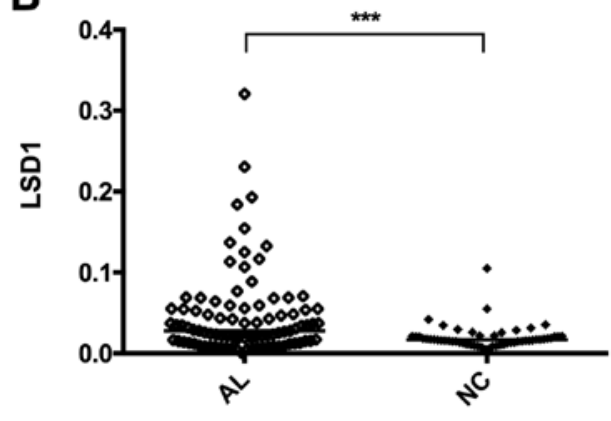

D

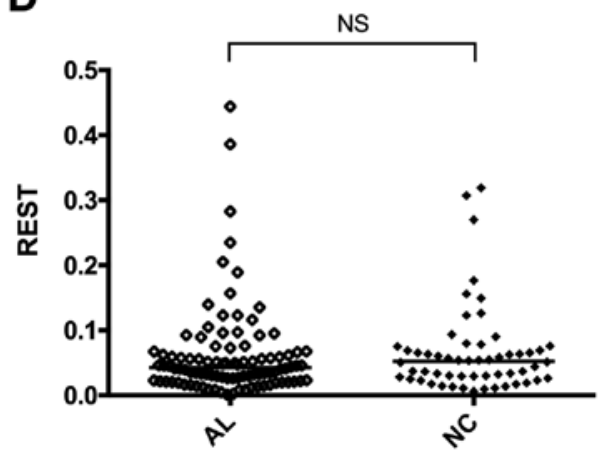

$\mathbf{F}$

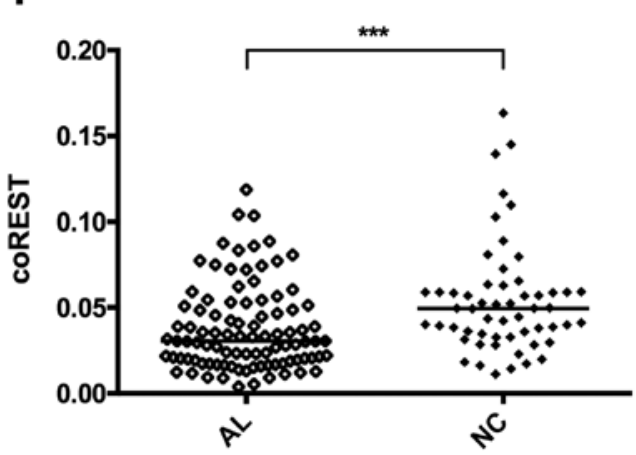

Figure 3. Expression levels of downstream genes in the HOTAIR signaling pathway. (A) Compared with normal controls, expression of EZH2 increases $\left({ }^{* * *} \mathrm{P}=0.0009\right.$, Mann-Whitney). (B) The expression of LSD1 increases $\left({ }^{* * *} \mathrm{P}=0.0003\right.$, Mann-Whitney). (C) The expression of SUZ12 show no significant differences ( $\mathrm{P}=0.5437$, Mann-Whitney). (D) The expression of REST show no significant differences ( $\mathrm{P}=0.4265$, Mann-Whitney). (E) The expression of EED decreases $\left({ }^{*} \mathrm{P}=0.0213\right.$, Mann-Whitney). (F) The expression of CoREST decreases $\left({ }^{* * *} \mathrm{P}=0.0003\right.$, Mann-Whitney).

remethylate demethylated $\mathrm{CpG}$ sites. We used RT-qPCR to detect expression of DNMT3A and DNMT3B. The results show that, compared with normal controls, the expression of DNMT3A in AL patients significantly increases $(\mathrm{P}=0.0002$;
Fig. 4A), as does DNMT3B ( $\mathrm{P}<0.0001$, Fig. 4B). Expression of these genes shows a significant positive correlation with high expression of HOTAIR (DNMT3A, r=0.4001, $\mathrm{P}=0.0003$; DNMT3B, r=0.7586, P<0.0001; Fig. 5C and D). 
A

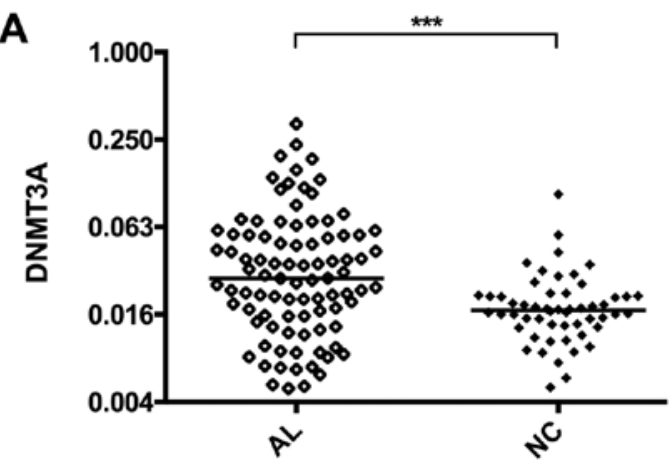

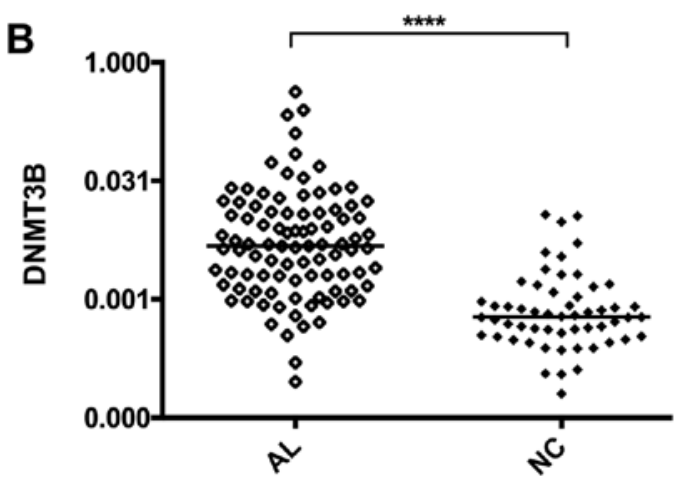

Figure 4.Expression of DNMT3A and DNMT3B.(A) Compared with normal controls, expression of DNMT3A in AL patients significantly increases ${ }^{* * * *} \mathrm{P}=0.0002$, Mann-Whitney). (B) The expression of DNMT3B in AL patients significantly increases ( ${ }^{* * * *} \mathrm{P}<0.0001$, Mann-Whitney).
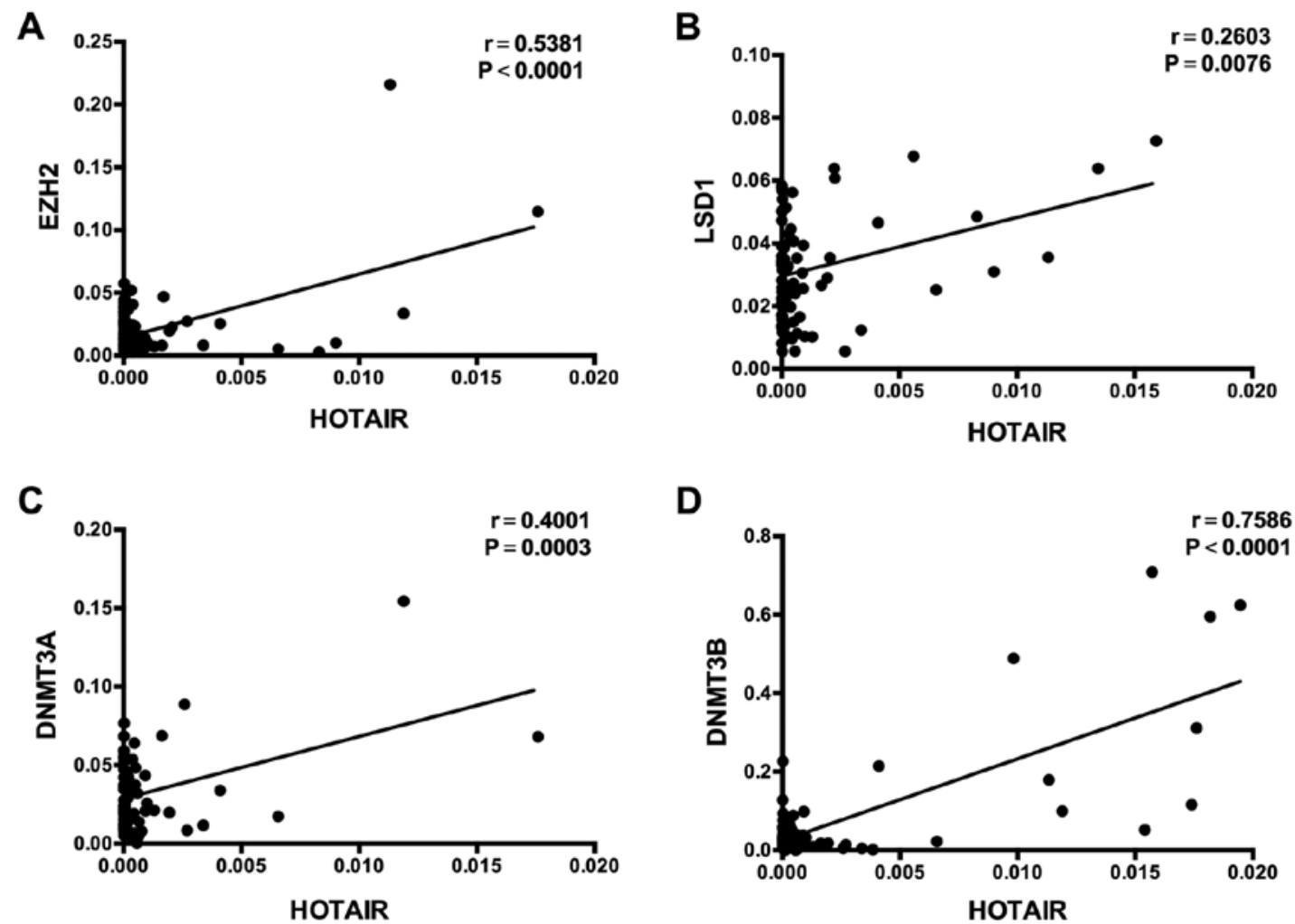

Figure 5. Association between expression of HOTAIR and downstream effector genes. (A-D) Linear regression was used to analyze expression of HOTAIR compared to EZH2, LSD1, DNMT3A and DNMT3B in AL patients. The results show a positive correlation. Spearman rank test (r) and P-values (two-tailed) are shown.

\section{Discussion}

Previous studies have assigned an oncogenic function to HOTAIR in a variety of tumors, findings supported in the present study of AL. Compared with controls, the expression of HOTAIR in M5 patients increased, while the difference in other types of leukemia patients did not reach statistical significance. Compared to patients with low expression, high expression of HOTAIR was closely associated with a poor prognosis in AL patients. Multivariate analysis showed that age, peripheral blood leucocyte count and high expression of HOTAIR were independent prognostic indicators for OS and EFS. In addition, the examination of downstream genes in the HOTAIR signaling pathway showed that the expression of EZH2, LSD1, DNMT3A and DNMT3B in AL patients significantly increased, and showed a significant positive correlation with high expression of HOTAIR. Based on these observations, we speculated that HOTAIR may participate in the development and progression of leukemia by mediating the methylation of DNA and histones.

Although multiple groups have examined the function of HOTAIR in tumorigenesis, its clinical significance and molecular mechanisms in AL patients were not previously fully elucidated. Wu et al (25) and Hao and Shao (26) analyzed the clinical features between HOTAIR and acute myeloid leukemia. Our research further strengthens the evidence 
linking high HOTAIR expression with poor prognosis in AL patients, and analyzed the relationship between HOTAIR and downstream effector genes. The present study found that, compared with normal controls, the expression of HOTAIR in M5 patients increased, while in other types of leukemia patients the difference did not reach statistical significance. We speculated that, with an increase in sample size, the expression of HOTAIR probably would increase in other types of AL. This will require further examination and an increased study size. In the present study we did not take into account the heterogeneity among different types of AL. Differences in expression of HOTAIR could be due to a different mechanism of action in different types of AL. We followed up the $\mathrm{AL}$ patients and conducted clinical observations, and found that the OS and EFS of patients with high expression of HOTAIR were significantly reduced. Multivariate analysis showed that high expression of HOTAIR is one of the risk factors predicting OS and EFS, suggesting that HOTAIR could be used as a molecular marker to predict leukemia and determine its prognosis.

Studies focused on PRC2 complexes found that transcription and activation of the complex in tumors was mediated by EZH2, indicating that the EZH2 plays an important role in function of the PRC2 complex. Overexpression of EZH2 was first documented by gene chip analysis in prostate and breast cancer $(27,28)$. Overexpression of EZH2 was closely related to invasiveness, eventual metastasis, poor clinical outcome and poor prognosis in a variety of tumors (28-30). A number of studies, however, have shown that the mechanisms involved in the overexpression of EZH2 are cell type-dependent. EZH2 plays an oncogenic role in most solid tumors through a variety of molecular mechanisms. Increased EZH2 leads to an increase in H3K27me3, thereby modifying and silencing the expression of tumor suppressor genes in tumor cells epigenetically, resulting in tumorigenesis. Increased EZH2 expression is involved in tumor development through multiple signaling pathways. For example, overexpression of the EZH2, MEK-ERK, and pRB-E2F signaling pathway is associated with the occurrence of breast cancer $(31,32)$. MYC and ETS transcription factors can directly regulate the transcription of EZH2 in prostate cancer $(33,34)$. In Ewing's sarcoma, the fusion oncoprotein EWS-FLI1 can induce the expression of EZH2, and plays a key role in the differentiation of the endothelium/neuroectoderm and in tumor growth (35). Paradoxically, recent studies have shown that mutations or deletions in PRC2 complex components may occur in some myelodysplastic syndromes (MDS) and myeloproliferative neoplasms. Altered expression of EZH2 in cancers may occur through complex mechanisms; the cellular environment influences activation of oncogenic pathways leading to epigenetic modifications promoting tumorigenesis $(36,37)$. The LSD1 subunit, which has a major catalytic function in the LSD1 complex, was the first identified histone demethylase. It is highly expressed in a variety of tumor cells and promotes the growth, metastasis and invasiveness of tumors, including prostate (38), breast (39), lung (40) and gastrointestinal cancer (41), and retinoblastoma (42). RNAi or small molecule inhibitors can inhibit the expression and activity of LSD1, leading to inhibition of tumor growth and metastasis. We examined the expression of the PRC2 complex (EZH2, SUZ12 and EED) and LSD1 complex (LSD1, REST and CoREST) in AL patients compared to normal controls in an attempt to understand their significance in leukemia. Our results showed that, compared with normal controls, the expression levels of EZH2 and LSD1 in AL patients increased, those of SUZ12 and REST showed no significant differences, and EED and CoREST decreased. We speculated that the EHZ2 and LSD1 subunits play important roles in the PRC2 and LSD1 complexes, respectively. HOTAIR could be involved in the development of leukemia through regulation of the PRC2 and LSD1 complexes and through mediating regulation of histone methylation. The reduced expression of EED and CoREST could be due to negative feedback or their participation in other regulatory processes. Elucidation of specific mechanisms will be examined in future studies by our group.

Methylation of genomic DNA is catalyzed and sustained by DNA methyltransferase (DNMT). In mammals, DNMT can be divided into three types based on structural and functional differences: DNMT1, DNMT2 and DNMT3 (43-45). The DNMT3 family includes DNMT3A, DNMT3B and the regulatory factor DNMT3L which participate in the process of remethylation of demethylated DNA (46). DNMT1 maintains methylation during DNA replication and repair, while the function of DNMT2 is not yet clear (47). Several studies have shown that abnormal DNA methylation is closely related to tumorigenesis and that the expression of DNMTs in cancerous tissues is increased $(48,49)$. However, histone methylation and DNA methylation were initially thought to be two separate gene silencing systems. Viré et al (50) found that PRC2 complexes co-immunoprecipitated with three transmethylases, and that silencing of specific genes required the joint participation of both EZH2 and DNA transmethylases. These findings revealed a direct relationship between the two key epigenetic systems. LSD1 also plays an important role in coordinating histones and DNA methylation by acting directly on histones and DNMT1 (51). Understanding the role of DNMTs and histone methylation in leukemia and exploring whether DNA methylation and histone methylation are jointly involved in the occurrence of the disease is particularly important. We examined the expression of DNMT3A and DNMT3B, and found that, compared with normal controls, the expression of DNMT3A and DNMT3B in AL patients significantly increased. This suggests that interactions between DNMTs and the PRC complex may occur in the process of gene silencing by DNA methylation, resulting in the development and progression of AL.

In conclusion, the present study examined the expression levels of HOTAIR, DNA methyltransferase and histone (de)methylase genes downstream of HOTAIR in AL patients. We found that the expression of HOTAIR in M5 patients increased and was closely related with a poor prognosis. In addition, the expression of EZH2, LSD1, DNMT3A and DNMT3B in AL patients significantly increased, and showed a significant positive correlation with the high expression of HOTAIR. Based on our findings, we suggest that HOTAIR may be involved in the development and progression of leukemia by mediating the methylation of DNA and histones. The present study provides a new perspective for the further exploration of biological functions of lncRNAs, and identifies novel targets involved in the development, progression and treatment of certain types of AL. 


\section{Acknowledgements}

The present study was supported by the National Natural Science Foundation of China (nos. 81370629 and 81300428), the Major Research of Fujian Medical University (09-ZD021), the Science and Technology Department of Fujian Province (2011Y4002), the Education Department of Fujian Province (JA10129), and the National and Fujian Provincial Key Clinical Specialty Discipline Construction Program (China).

\section{References}

1. Liu YQ, Zhao FJ, Chen WQ, et al: An analysis of incidence and mortality of leukemia in China, 2009. China Cancer 7: 528-534, 2013.

2. Muto T, Sashida G, Oshima M and Iwama A: Mutations of epigenetic regulator genes and myeloid malignancies. Rinsho Ketsueki 56: 2287-2294, 2015 (In Japanese).

3. Chalei V, Sansom SN, Kong L, Lee S, Montiel JF, Vance KW and Ponting CP: The long non-coding RNA Dali is an epigenetic regulator of neural differentiation. eLife 3: e04530, 2014.

4. Lee DH, Singh P, Tsai SY, Oates N, Spalla A, Spalla C, Brown L, Rivas G, Larson G, Rauch TA, et al: CTCF-dependent chromatin bias constitutes transient epigenetic memory of the mother at the H19-Igf 2 imprinting control region in prospermatogonia. PLoS Genet 6: e1001224, 2010.

5. Haemmerle $M$ and Gutschner T: Long non-coding RNAs in cancer and development: Where do we go from here? Int J Mol Sci 16: 1395-1405, 2015.

6. Guttman M, Donaghey J, Carey BW, Garber M, Grenier JK, Munson G, Young G, Lucas AB, Ach R, Bruhn L, et al: lincRNAs act in the circuitry controlling pluripotency and differentiation. Nature 477: 295-300, 2011.

7. Li X, Wu Z, Fu X and Han W: lncRNAs: Insights into their function and mechanics in underlying disorders. Mutat Res Rev Mutat Res 762: 1-21, 2014.

8. Rinn JL, Kertesz M, Wang JK, Squazzo SL, Xu X, Brugmann SA, Goodnough LH, Helms JA, Farnham PJ, Segal E, et al: Functional demarcation of active and silent chromatin domains in human HOX loci by noncoding RNAs. Cell 129: 1311-1323, 2007.

9. Gupta RA, Shah N, Wang KC, Kim J, Horlings HM, Wong DJ, Tsai MC, Hung T, Argani P, Rinn JL, et al: Long non-coding RNA HOTAIR reprograms chromatin state to promote cancer metastasis. Nature 464: 1071-1076, 2010.

10. Bhan A,Hussain I, Ansari KI, Kasiri S, Bashyal A and Mandal SS: Antisense transcript long noncoding RNA (IncRNA) HOTAIR is transcriptionally induced by estradiol. J Mol Biol 425: 3707-3722, 2013.

11. Chisholm KM, Wan Y, Li R, Montgomery KD, Chang HY and West RB: Detection of long non-coding RNA in archival tissue: Correlation with polycomb protein expression in primary and metastatic breast carcinoma. PLoS One 7: e47998, 2012.

12. Wu ZH, Wang XL, Tang HM, Jiang T, Chen J, Lu S, Qiu GQ, Peng ZH and Yan DW: Long non-coding RNA HOTAIR is a powerful predictor of metastasis and poor prognosis and is associated with epithelial-mesenchymal transition in colon cancer. Oncol Rep 32: 395-402, 2014.

13. Ye P, Wang T, Liu WH, Li XC, Tang LJ and Tian FZ: Enhancing HOTAIR/MiR-10b drives normal liver stem cells toward a tendency to malignant transformation through inducing epithelial-to-mesenchymal transition. Rejuvenation Res 18: 332-340, 2015.

14. Zhuang Y, Wang X, Nguyen HT, Zhuo Y, Cui X, Fewell C, Flemington EK and Shan B: Induction of long intergenic noncoding RNA HOTAIR in lung cancer cells by type I collagen. $\mathrm{J}$ Hematol Oncol 6: 35, 2013.

15. Kim K, Jutooru I, Chadalapaka G, Johnson G, Frank J, Burghardt R, Kim S and Safe S: HOTAIR is a negative prognostic factor and exhibits pro-oncogenic activity in pancreatic cancer. Oncogene 32: 1616-1625, 2013.

16. Nie Y, Liu X, Qu S, Song E, Zou H and Gong C: Long non-coding RNA HOTAIR is an independent prognostic marker for nasopharyngeal carcinoma progression and survival. Cancer Sci 104: 458-464, 2013.
17. Nakagawa T, Endo H, Yokoyama M, Abe J, Tamai K, Tanaka N, Sato I, Takahashi S, Kondo T and Satoh K: Large noncoding RNA HOTAIR enhances aggressive biological behavior and is associated with short disease-free survival in human non-small cell lung cancer. Biochem Biophys Res Commun 436: 319-324, 2013.

18. Simon JA and Lange CA: Roles of the EZH2 histone methyltransferase in cancer epigenetics. Mutat Res 647: 21-29, 2008.

19. Lee MG, Wynder C, Cooch $\mathrm{N}$ and Shiekhattar R: An essential role for CoREST in nucleosomal histone 3 lysine 4 demethylation. Nature 437: 432-435, 2005.

20. Shi YJ, Matson C, Lan F, Iwase S, Baba T and Shi Y: Regulation of LSD1 histone demethylase activity by its associated factors. Mol Cell 19: 857-864, 2005.

21. Shi Y, Lan F, Matson C, Mulligan P, Whetstine JR, Cole PA, Casero RA and Shi Y: Histone demethylation mediated by the nuclear amine oxidase homolog LSD1. Cell 119: 941-953, 2004.

22. Tsai MC, Manor O, Wan Y, Mosammaparast N, Wang JK, Lan F, Shi Y, Segal E and Chang HY: Long noncoding RNA as modular scaffold of histone modification complexes. Science 329: 689-693, 2010

23. Döhner H, Estey EH, Amadori S, Appelbaum FR, Büchner T, Burnett AK, Dombret H, Fenaux P, Grimwade D, Larson RA, et al; European LeukemiaNet: Diagnosis and management of acute myeloid leukemia in adults: Recommendations from an international expert panel, on behalf of the European LeukemiaNet. Blood 115: 453-474, 2010.

24. Kogo R, Shimamura T, Mimori K, Kawahara K, Imoto S, Sudo T, Tanaka F, Shibata K, Suzuki A, Komune S, et al: Long noncoding RNA HOTAIR regulates polycomb-dependent chromatin modification and is associated with poor prognosis in colorectal cancers. Cancer Res 71: 6320-6326, 2011.

25. Wu S, Zheng C, Chen S, Cai X, Shi Y, Lin B and Chen Y: Overexpression of long non-coding RNA HOTAIR predicts a poor prognosis in patients with acute myeloid leukemia. Oncol Lett 10: 2410-2414, 2015.

26. Hao S and Shao Z: HOTAIR is upregulated in acute myeloid leukemia and that indicates a poor prognosis. Int J Clin Exp Pathol 8: 7223-7228, 2015.

27. Ku M, Koche RP, Rheinbay E, Mendenhall EM, Endoh M, Mikkelsen TS, Presser A, Nusbaum C, Xie X, Chi AS, et al: Genomewide analysis of PRC1 and PRC2 occupancy identifies two classes of bivalent domains. PLoS Genet 4: e1000242, 2008.

28. Varambally S, Dhanasekaran SM, Zhou M, Barrette TR, Kumar-Sinha C, Sanda MG, Ghosh D, Pienta KJ, Sewalt RG, Otte AP, et al: The polycomb group protein EZH2 is involved in progression of prostate cancer. Nature 419: 624-629, 2002.

29. Kleer CG, Cao Q, Varambally S, Shen R, Ota I, Tomlins SA, Ghosh D, Sewalt RG, Otte AP, Hayes DF, et al: EZH2 is a marker of aggressive breast cancer and promotes neoplastic transformation of breast epithelial cells. Proc Natl Acad Sci USA 100: 11606-11611, 2003.

30. Collett K, Eide GE, Arnes J, Stefansson IM, Eide J, Braaten A, Aas T, Otte AP and Akslen LA: Expression of enhancer of zeste homologue 2 is significantly associated with increased tumor cell proliferation and is a marker of aggressive breast cancer. Clin Cancer Res 12: 1168-1174, 2006.

31. Fujii S, Tokita K, Wada N, Ito K, Yamauchi C, Ito Y and Ochiai A: MEK-ERK pathway regulates EZH2 overexpression in association with aggressive breast cancer subtypes. Oncogene 30: 4118-4128, 2011.

32. Bracken AP, Pasini D, Capra M, Prosperini E, Colli E and K: EZH2 is downstream of the pRB-E2F pathway, essential for proliferation and amplified in cancer. EMBO J 22: 5323-5335, 2003.

33. Kunderfranco P, Mello-Grand M, Cangemi R, Pellini S Mensah A, Albertini V, Malek A, Chiorino G, Catapano CV and Carbone GM: ETS transcription factors control transcription of EZH2 and epigenetic silencing of the tumor suppressor gene Nkx3.1 in prostate cancer. PLoS One 5: e10547, 2010.

34. Koh CM, Iwata T, Zheng Q, Bethel C, Yegnasubramanian S and De Marzo AM: Myc enforces overexpression of EZH2 in early prostatic neoplasia via transcriptional and post-transcriptional mechanisms. Oncotarget 2: 669-683, 2011.

35. Richter GH, Plehm S, Fasan A, Rössler S, Unland R, Bennani-Baiti IM, Hotfilder M, Löwel D, von Luettichau I, Mossbrugger I, et al: EZH2 is a mediator of EWS/FLI1 driven tumor growth and metastasis blocking endothelial and neuro-ectodermal differentiation. Proc Natl Acad Sci USA 106: 5324-5329, 2009. 
36. Ntziachristos P, Tsirigos A, Van Vlierberghe P, Nedjic J, Trimarchi T, Flaherty MS, Ferres-Marco D, da Ros V, Tang Z, Siegle $\mathrm{J}$, et al: Genetic inactivation of the polycomb repressive complex 2 in T cell acute lymphoblastic leukemia. Nat Med 18: 298-301, 2012.

37. Zhang J, Ding L, Holmfeldt L, Wu G, Heatley SL, Payne-Turner D, Easton J, Chen X, Wang J, Rusch M, et al: The genetic basis of early T-cell precursor acute lymphoblastic leukaemia. Nature 481: 157-163, 2012.

38. Metzger E, Wissmann M, Yin N, Müller JM, Schneider R, Peters AH, Günther T, Buettner R and Schüle R: LSD1 demethylates repressive histone marks to promote androgenreceptor-dependent transcription. Nature 437: 436-439, 2005.

39. Lim S, Janzer A, Becker A, Zimmer A, Schüle R, Buettner R and Kirfel J: Lysine-specific demethylase 1 (LSD1) is highly expressed in ER-negative breast cancers and a biomarker predicting aggressive biology. Carcinogenesis 31: 512-520, 2010.

40. Lv T, Yuan D, Miao X, Lv Y, Zhan P, Shen X and Song Y: Over-expression of LSD1 promotes proliferation, migration and invasion in non-small cell lung cancer. PLoS One 7: e35065, 2012.

41. Chen C, Zhao M, Yin N, He B, Wang B, Yuan Y, Yu F, Hu J, Yin $\mathrm{B}$ and $\mathrm{Lu} \mathrm{Q}$ : Abnormal histone acetylation and methylation levels in esophageal squamous cell carcinomas. Cancer Invest 29: 548-556, 2011

42. Yokoyama A, Takezawa S, Schüle R, Kitagawa H and Kato S: Transrepressive function of TLX requires the histone demethylase LSD1. Mol Cell Biol 28: 3995-4003, 2008.

43. Bestor TH: The DNA methyltransferases of mammals. Hum Mol Genet 9: 2395-2402, 2000.

44. Chedin F, Lieber MR and Hsieh CL: The DNA methyltransferase-like protein DNMT3L stimulates de novo methylation by Dnmt3a. Proc Natl Acad Sci USA 99: 16916-16921, 2002.
45. Chen T and Li E: Establishment and maintenance of DNA methylation patterns in mammals. Curr Top Microbiol Immunol 301: 179-201, 2006

46. Gowher H, Liebert K, Hermann A, Xu G and Jeltsch A: Mechanism of stimulation of catalytic activity of Dnmt3A and Dnmt3B DNA-(cytosine-C5)-methyltransferases by Dnmt3L. J Biol Chem 280: 13341-13348, 2005.

47. Margot JB, Cardoso MC and Leonhardt H: Mammalian DNA methyltransferases show different subnuclear distributions. J Cell Biochem 83: 373-379, 2001.

48. Robaina MC, Mazzoccoli L, Arruda VO, Reis FR, Apa AG, de Rezende LM and Klumb CE: Deregulation of DNMT1, DNMT3B and miR-29s in Burkitt lymphoma suggests novel contribution for disease pathogenesis. Exp Mol Pathol 98: 200-207, 2015

49. Pathania R, Ramachandran S, Elangovan S, Padia R, Yang $\mathrm{P}$, Cinghu $\mathrm{S}$, Veeranan-Karmegam R, Arjunan $\mathrm{P}$, Gnana-Prakasam JP, Sadanand F, et al: DNMT1 is essential for mammary and cancer stem cell maintenance and tumorigenesis. Nat Commun 6: 6910, 2015.

50. Viré E, Brenner C, Deplus R, Blanchon L, Fraga M, Didelot C, Morey L, Van Eynde A, Bernard D, Vanderwinden JM, et al: The Polycomb group protein EZH2 directly controls DNA methylation. Nature 439: 871-874, 2006.

51. Wang J, Hevi S, Kurash JK, Lei H, Gay F, Bajko J, Su H, Sun W, Chang H, Xu G, et al: The lysine demethylase LSD1 (KDM1) is required for maintenance of global DNA methylation. Nat Genet 41: 125-129, 2009. 